\title{
New World of Marketing: Use of Social Networking Sites
}

\author{
S. Saravana Kumar \& Dr.Y.Rajaram \\ Research \& Development Centre, Bharathiar University, Coimbatore-641 046
}

\begin{abstract}
Among the various communications method used traditionally by an company is changed dramatically after the emergence of social media. Widely used tool to communicate with hundreds or even thousands of other people about products or product updations and the companies that provide them. As is evident from data available in public domain, social media is a blessing for the marketing fraternity in taking their brand to the masses. It also provides a major impact on consumer to consumer communications. This article argues that social media is a new tool of the promotion mix because in a traditional sense it enables companies to talk to their customers, while in a nontraditional sense it enables customers to talk directly to one another. This article provides managers with a better understanding of social media and a framework for incorporating it into their IMC strategies, thus more effectively communicating with their target markets
\end{abstract}

\section{Introduction}

The recent election campaign projecting Narendra Modi, proved beyond doubt the growing power of social media in the Indian context. The campaign managers of the Prime Minister amply and ably put to use the social media platforms in an attempt to create the mass hysteria that was on offer in the run up to election days across the country. This was probably one of the best use of social media in politics the country has witnessed in recent times. The way brand Modi was constructed and developed across Facebook, Twitter, Instagram and the likes is a case study worth analyzing by brand builders. It is therefore not astonishing to note that the Prime Ministers victory message was retweeted the maximum number of times, something India had never witnessed before (Chilkoti, 2014). This is not a mere occurance but an amplification of the power of social media.

Examples of efficient use of the social media and its ensuing effects are not restricted to the political sphere. A growing number of corporate campaigns are also moving online and the results have been encouraging and signal the potential of this medium. A case in point is the campaign undertaken by Ranbaxy to celebrate Women's Day (Hingwala, 2013). The campaign meant to appreciate the contribution of women in their lives by patting their backs via a Facebook application. Ranbaxy shared all the appreciations received with the women concerned making them special for their contributions. Social media platform was so effectively utilized that nearly 10,000 women received appreciation within seven days of the launch of the campaign (Hingwala, 2013). The two cases presented above is just the tip of the iceberg. It amplifies the opinion of marketing guru Philip Kotler who observed that the era of mass marketing revolving around advertisement and TV commercials is nearly over.

\section{The growth of social media}

It can be stated beyond doubt that technological advancements has shrunk the world. The obvious of distances and geographical boundaries has reduced over time. For corporations today, the time taken to disseminate information from one source to recipients far and wide has significantly reduced (ITU News, 2010). Social networking helps in constant sharing of updates, opinions and information across the globe. Within seconds inputs get transferred from one terminal to the other. A lot of businesses are now conducted online. Even serious business like disaster management and response are being increasingly coordinated online (ITU News, 2010). Hence it will not be prudent to overlook the power of social media in brand building, what ever the product maybe. Changing lifestyle and aspirations has positively impacted the growth of social media across the world. Going by statistics currently available, it can be derived that one out of every seven people access one social networking platform at least once every month (Gaudin, 2013). The number of users accessing social networking sites is expected to be over 2 billion in another couple of years (Gaudin, 2013). This is a huge opportunity for marketers to interact and engage with their target audiences. If numbers are any indication, the growth of social networking sites is on the rise and the trend is envisaged to continue over the next few years. Comparing the number of users of social media sites in 2013 vis-à-vis 2012 supports the above assumption ( Duggan \& Smith, 2013). All social networking platforms recorded increased traffic in 2013 compared to 2012. While Facebook registered an increase of $4 \%$ users, Pinterest recorded an increase of $6 \%$ and Twitter an increase of $2 \%$ (Duggan \& Smith, 2013). Bearing in mind that this percentage increase is a global phenomenon the number it translated into is significant. In other words, millions are getting added every year to the existing pool. Hence there are billions out there to be informed and influenced. And if results of campaigns successful on the net are anything to go by, the outcomes can be the most favorable for any organization. 


\section{The Indian Scenario}

In India the percentage of internet users who access social media platforms is pegged at $84 \%$ (EstatsIndia, 2013). In numeric about 110 million users in India access social media platforms like Facebook, Twitter, LinkedIn and others. While these already enjoy mass following platforms like Pinterest are virgins in this country. Hence there is scope to create awareness about these platforms and use them for information dissemination among the customers at large. However it might be prudent to take note that social networking popularity is still restricted to urban and semi-urban India. Hence the demographics and their careful consideration are required (EstatsIndia, 2013).

Young India is more skewed towards social media. This translates into a significant number because $65 \%$ of the country's population falls in the age group of 16 to 44 years (EstatsIndia, 2013). Such youths constantly share information with their peer group and often act as influencers in the decision making process of their friends and acquaintances. This facet is important for organizations for this group holds the key to the future of the country and also many organizations. Going back to the example of the electioneering on the social media, Narendra Modi's managers were able to develop suitable messages and campaigns to address the issues and aspirations of this section, which did have its influence of the outcome of the election process. This explains why the power and relevance of India's youth population online cannot be overlooked.

\section{Corporate relevance}

With an increasing number of customers preferring the social media for gathering information about businesses and products, companies are fast realizing the importance and potentials of a noticeable online presence (Hendricks, 2014). Positive buzz on this medium is becoming crucial for building customer interest and loyalty towards products and brands. Analysis of ad revenues generated by social networking platforms is significant. Globally revenues from advertisement were poised to record a 54\% growth in the year 2013 (EstatsIndia, 2013). Advertisement spend was studied to be around $\$ 9.2$ billion for the period. This means that an increasing number of corporate are turning their attention and building their marketing strategies considering effective use of these new communication mediums. Promotion on popular networking sites is gaining fast acceptance. Media budget of companies are now judiciously proportioned between traditional media and new age social media like networking platforms. The word-of-mouth generated real time, does influence customer decision towards acceptance and rejection of a product or brand.

But is the social media platform suitable for all corporate and product categories? New startups are resorting to social media in a big way (Hendricks, 2014). Given the budgetary constraints, they find new age media platform much cost effective to present their products and services to potential customers. This helps companies save capital for more integral business purposes and yet create a buzz about their offerings which leads to interest, enquiry and probable final purchase. As the buzz gets stronger more probable get attracted to the product or service helping build customer enthusiasm and subsequent customer loyalty. A survey by the popular social networking site LinkedIn found that $81 \%$ small and medium sized businesses are resorting to social media platforms for their marketing and advertisement requirements (Wagner, 2014). It is not surprising that companies looking at social media do it to create awareness among customers about their products and services. In other words, marketing teams are visible dependent on social media as compared to other teams like purchase or sales.

Even companies which are on a growth trajectory cannot afford to overlook social media as a platform of customer engagement. The research initiative further observed that $91 \%$ of companies which are growing year after year are using social media to heighten awareness about their brand (Wagner, 2014). 82\% companies reported new leads as result of such social media engagement. Such findings and reports supports the growing belief in the power of social media as an integral part of the marketing strategy and design of a company.

\section{Successful Campaigns}

Over the years many companies have conducted specific campaigns on social networking platforms as a part of their brand building exercise. Often these campaigns are planned around a particular date which is of significance among customers. The Song for Sister, Made with Love campaign conducted by Cadbury is a classic example (Hingwala, 2013). This campaign celebrated the bond between brother and sister in a fresh, special way. Centered on Raksha Bandhan, the Songs for Sister aimed at replacing traditional gifts with chocolates as a part of celebrations. All interested participants were required to pen a message for their beloved sisters to which tunes were added subsequently. The songs were obviously special for sisters and also for the brothers who penned the songs. The campaign went viral and increased participation and helped the brand connect with the brothers and sisters in a special and humane way. Such campaigns not only create awareness but also provide brands with specific characteristics. The April 2013 campaign conducted by Dove is another interesting example of how social media campaign can increase engagement (David, 2013). The campaign was named around the attributes of beauty depicted through sketches. The campaign ended with revelation of the 
sketches to women they were based on. The sketches were drawn by experts of FBI. One of the sketches was drawn on description provided the woman being drawn while the other sketch was based on inputs provided by an acquaintance of the woman. Both sketches were then revealed to the subject and the difference between the two sketches was noteworthy. While the drawing based on inputs of the subject focused more on the flaws, the one based on description of acquaintances focused more on the beauty of the person. This campaign went viral on the social networking platform and the initiative has already clocked nearly 115 million views globally (David, 2013). This happened within a month of the launch of the campaign and till date this is the most shared online video of all times. Data proves the success of this campaign and how it boosted the brand image and recall of Dove's association with beauty and glamour.

\section{Pillars of brand building}

Social media provides a great platform for consumer connect and interaction for any brand. It is undoubtedly a more dynamic medium, compared to traditional communication channels for brand building and brand image enhancement. Social media helps in connecting a brand and its audience emotionally which strengthens the bond (Costa, 2013). Though social media initiatives take time to bear fruits, their relevance can never be debated. But for it to be effective, social media strategies should be formulated deftly and the mediums selected after careful consideration of all facets. Such initiatives should be undertaken with a genuine will and interest (Costa, 2013). Popular social networking platforms have opened by enormous opportunities for marketers to position and strengthen their brands. Such can be attributed to the very nature of such channels like interactivity, penetration, speed and acceptance. Experts have drawn up suggested approach to make the most of social networking channels:

- Social media interventions should be formulated and executed with a vision and sense of purpose. It is important to get across the message of a brand in the most powerful way possible. This helps build credibility and trust among target customers (Hutchinson, 2014). The virtual nature of the medium makes trust the all important foundation on which business is to proceed. Hence brands should demonstrate their belief and credibility through the campaigns undertaken on social media. Messages should be developed bearing in mind the target audience, their demography and preferences.

- Having a finger on the pulse is important for implementing successful brand building initiatives on the net, is vital. This helps precise understanding of customer behavior and changing preferences according to which campaigns can be tailor-made or altered for maximum impact and result.

- Brands should have clear positioning to be able to build a niche among customers. This is imperative when brand building is undertaken through networking sites. Customers should understand what the brand stands for and what its USP is. Facilitation of discussion, sharing and word-of-mouth is possible when the brand philosophy is clear to the target. Marketers should therefore spare extra effort to showcase the brand values and its contribution in making life better for the customer through undertaken initiatives. Only brands which are respected are all brands enhancing lifestyles.

- To be seen and heard on social media is as important as any of the above (Hutchinson, 2014). To be successful marketers should interact with customers through networking channels. It provides them the opportunity to listen to majority view, an evaluation of brand acceptance level. This information is beneficial for developing strategies for it is heard from the horse's mouth. Companies should therefore be active and aggressive in exploring the full gamut of social media in creating a unique brand experience for customers.

\section{Advantages of social media}

As is evident from data available in public domain, social media is a blessing for the marketing fraternity in taking their brand to the masses. Many companies have successfully used social media to expand their business and retain customer loyalty. The most important advantage of social media is the communication openness it offers. It is now easier for marketers to place the brand in direct communication with the customers leading to exchange of product information, feedback, reviews, suggestion all of which provide strategic inputs for future initiatives (Beard, 2009).

Social media offers cost effective medium to businesses to market their products and services and has the potential of reaping greater benefits than traditional media. This explains why SMEs skew towards resorting to social media for their marketing initiatives. Being a dynamic medium it's always active, easily implementable and offers great shelf file to campaigns (Grunert, 2009). Information about products and services can be made easily available to customers and in many cases such hosting platforms are offered free (Brooger, 2010). Hence companies find it economical to execute social media campaigns. A solution to geographical limitations, social media offers a global market to any product or service at any point of time (Karimi, 2009). Companies can take their brands across to millions of international viewers within moments and this has the potential of providing critical push to a brand growth and image. 


\section{Shortcomings of the medium}

Not baring its contribution is building stronger brand image, brand marketing through social networking platforms has its inherent risks as well. The very transparency which is a boon for many marketers can turn nightmare for many. Any negative comment or message about a product, service or company can ruin the image or business of the same (Karimi, 2009). Since very little control can exercised over who's posting what unless all sites are moderated, nipping negative publicity in the bud is a challenge. The huge expanse and scope of the social medium makes it practically impossible to track any negative feelings within customers, unless surfaced. This aspect should be focused on while selecting the appropriate social media channel.For those interested in analyzing hit to sale conversion, tracking is an issue. It's again a difficult proposition to know the source of awareness and influence of purchase decision making for each and every customer online. Since the gestation period is high for social media usage, the proper evaluation of effort to quickness of conversion becomes difficult.

Engagement through social networking sites is often time consuming and required dedicated manpower to monitor and update it regularly (Brooger, 2010). So while the medium is cost effective, manpower costs may increase because of social media preferences for marketing.Employee addiction to such medium is also a problem faced in the implementation of social networking for brand building. Such addiction can lead to loss of production man hours (Niharikas, 2010). Distracted employees can err in their jobs having serious consequences for the company. Hence development of social media culture and mindset within the company is important and this requires leadership and guidance from the senior management.Having the right resources to plan and execute relevant campaigns is a priority for companies how have effectively used and plan to use social media for building their brands. Given the medium, the team should have the competencies to develop dynamic campaigns which are innovative, appeal to customers, engage and inform them.

\section{Conclusion}

Philip Kotler got it right when he foretold the impending death of traditional media attributed to the growth of the social media platform. Companies across the world have embraced social media like never before. Any thinkable product or service is available on the net. For difficulties, there are solutions galore on the networking sites. Any assistance one needs there are willing hands to help all around. The power of social media is today being felt all the more, give the existing pace of life.It's therefore not surprising for companies to ensure a strong presence on the social media to be there when the hour arrives. Realizing the way technology has impacted daily life, companies are pulling all strings to have a formidable social media presence. The soaring ad revenues indicate significant ad budgets being allocated towards brand building through social networking sites. While it keeps the cash registers ringing it also facilitates information inflow for any company. This helps companies understand customer likings and also equips them to predict any likely change in customer outlook providing an opportunity for companies to alter their products or services, systems, application or style of functioning. The way information is available and shared through social media is unthinkable from a traditional media stand point. If strategized prudently, monitored and implemented deftly social media is the new marketing tool that can change the way the business of marketing functions.

\section{References}

[1]. Beard, A. (2009). The Pros \& Cons of Social Networking as a business. Gooruze. Retrieved from http://www. gooruze. com/articles/1682/The-Pros--Con-of-Social-Networking-as-a-business

[2]. Brooger. (2009). Using social networking sites for business marketing: Advantages and disadvantages. Brooger. Retrieved from http://brooger.com/business-finance-money.php/using-social-networking-sites-for-business-marketing-advantages-and disadvantages

[3]. Chilkoti, A. (2014). Narendra Modi to be India's first social prime minister. Financial Times, May 23 $3^{\text {rd }}$. Retrieved from http://www. ft. com/cms/s/0/e347de5c-e088-11e3-9534-00144feabdc0.html\#axzz3FuW83dch

[4]. Costa, J. (2013). Brand Building: Connecting With Consumers through Social Media. Huffington Post. Retrieved from http://www. huffingtonpost.com/jose-costa/brand-building_b_3950341.html

[5]. David, E. (2013). Top 10 Influential Social Media Marketing Campaigns of 2013. Adhere Creative. Retrieved from http://www. adherecreative.com/blog/bid/152638/Top-10-Influential-Social-Media-Marketing-Campaigns-of-2013

[6]. Duggan, M. and Smith, A. (2013). Social Media Update 2013. Pew Research Internet Project. Retrieved from http://www. pewinternet.org/2013/12/30/social-media-update-2013/

[7]. Gaudin, S. (2013). One out of seven people use social networks, study shows. Computerworld. Retrieved from http://www. computerworld. com/article/2486224/social-media/one-out-of-seven-people-use-social-networks--study-shows.html

[8]. Grunert, J. (2009). Effective Social Networking Marketing Strategies. Suite101. Retrieved from http://www. suite101. com/content/ effective-social-networking-marketing-strategies_a121975

[9]. Hendricks, D. (2014). 3 Ways Social Media Is Driving a Business Revolution. Forbes. Retrieved from http://www. forbes. com/sites/drewhendricks/2014/02/25/3-ways-social-media-is-driving-a-business-revolution/

[10]. Hingwala, N. (2013). 25 Best Indian Social Media Campaigns of 2013. Retrieved from http://www.socialsamosa.com/2013/12/25best-indian-social-media-campaigns-2013/

[11]. Hutchinson, A. (2014). Three Key Elements in Building Your Brand through Social Media. Social Mail Today. Retrieved from http://www. socialmediatoday.com/content/three-key-elements-building-your-brand-through-social-media 
[12]. Karimi, S. (2009). Pros and Cons of Using Facebook to Promote Your Business Online. Hubpages. Retrieved from http://hubpages. com/hub/Pros-and-Cons-of-Using-Facebook-to-Promote-Your-Business-Online

[13]. Niharikas. (2010). Pros and Cons of Social Networking Websites. Bukisa. Retrieved from http://www.bukisa.com/articles/ 396327_pros-and cons-of-social-networking-sites-for-business-marketing-advantages-and-disadvantages

[14]. The rise of social networking, (2010). ITU News. Retrieved from http://www.itu.int/net/itunews/issues/2010/06/35.aspx

[15]. Social Media Users \& Usage in India 2014. EstatsIndia. Retrieved from http://www.slideshare.net/Vicks18/social-media-usersusage-in-india-2014-report

[16]. Wagner, K. (2014). LinkedIn: 81\% of Small and Medium-Sized Businesses Use Social Media. Mashable. Retrieved from http://mashable.com/2014/02/13/linkedin-social-media-study/ 